TITLE:

\title{
Evaluating damage extent of fractured beams in steel moment- resisting frames using dynamic strain responses
}

\author{
AUTHOR(S): \\ Li, Xiaohua; Kurata, Masahiro; Nakashima, \\ Masayoshi
}

\section{CITATION:}

Li, Xiaohua ...[et al]. Evaluating damage extent of fractured beams in steel momentresisting frames using dynamic strain responses. Earthquake Engineering and Structural Dynamics 2015, 44(4): 563-581

\section{ISSUE DATE:}

2015-04

URL:

http://hdl.handle.net/2433/265292

\section{RIGHT:}

This is the peer reviewed version of the following article: [Evaluating damage extent of fractured beams in steel moment-resisting frames using dynamic strain responses, Earthquake Engineering and Structural Dynamics, 44(4) 563581], which has been published in final form at https://doi.org/10.1002/eqe.2536. This article may be used for noncommercial purposes in accordance with Wiley Terms and Conditions for Use of Self-Archived Versions.; The full-text file will be made open to the public on 29 December 2015 in accordance with publisher's 'Terms and Conditions for Self-Archiving'; This is not the published version. Please cite only the published version. この論文は出版社版でありませ ん。引用の際には出版社版をご確認ご利用ください。 


\title{
Evaluating damage extent of fractured beams in steel moment-resisting frames using dynamic strain responses
}

\author{
Xiaohua $\mathrm{Li}^{1}$, Masahiro Kurata ${ }^{2}$, and Masayoshi Nakashima ${ }^{2}$ \\ ${ }^{1}$ Department of Architecture and Architectural Engineering, Kyoto University, Kyoto, Japan \\ ${ }^{2}$ Disaster Prevention Research Institute, Kyoto University, Kyoto, Japan
}

Delays in the post-earthquake safety estimations of important buildings significantly increase unnecessary disorder in economic and social recovery following devastating earthquakes. Providing promptness and objectivity in evaluation procedures, damage detection through a structural health monitoring system using sensors attracts attention from building owners and other stakeholders. Nonetheless, local damage on individual structural elements is not easily identifiable, as such damage weakly relates to the global vibrational characteristics of buildings. The primary objectives of this research are to present and verify a method that quantifies the amount of local damage (i.e., fractures near beam-column connections) for the health monitoring of steel moment-resisting frames that have undergone a strong earthquake ground motion. In this paper, a novel damage index based on the monitoring of dynamic strain responses of steel beams under ambient vibration before and after earthquakes is firstly presented. Then, the relation between the amount of local damage and the presented damage index is derived numerically with a parametric study using a nine-story steel moment-resisting frame model designed for the SAC project. Finally, the effectiveness of the damage index and an associated wireless strain sensing system are examined with a series of vibration tests using a five-story steel frame testbed.

KEY WORDS: damage quantification; steel moment-resisting frames; dynamic strain; wireless sensing

\section{INTRODUCTION}

Knowing the location of damaged members and their extent of damage reduces uncertainty in evaluating the remaining capacity of earthquake-affected buildings and allows non-conservative decision-making on re-occupancy which may involve prioritized repairs. Nevertheless, the inspection of primary structural members, which are often covered with fire-proofing and architectural finishes, using non-destructive evaluation (NDE) techniques such as visual examination and ultrasonic testing require extensive costs and labors. Moreover, in the 1994 Northridge and 1995 Kobe earthquakes, where a large number of steel moment-resisting frames suffered fractures at welded beam-column connections [1,2], while many damaged connections were discovered, a lot of connections that remained undamaged had to undergo inspection owing to apparent damage in concrete slabs or nonstructural elements around these connections. 
Structural health monitoring (SHM), developed as a sophisticated technology for damage identification, has the potential to provide rapid and reliable information about seismic damage in a structure, and thus to avoid unnecessary inspections and downtime that hinder economic and social recovery following a devastating earthquake. Using measured vibration responses, various damage detection methods to date have been proposed, such as modal parameter-based method [3], inter-story drift ratio-based method [4], seismic wave propagation method [5], and time series analysis method [6]. At present, only a few important buildings located in earthquakeprone regions have installed SHM systems as an extension of strong ground motion monitoring systems in which the maximum floor responses and the changes in modal properties are primarily utilized for estimating the damage of buildings [7, 8]. However, damage estimation based on the global characteristics of buildings can only provide rough assessments due to large uncertainties in the hysteresis behaviors of individual members and connections. They are hardly effective to give reliable information for local damage on individual members (e.g., local buckling and fracture in steel moment-resisting frames) as such local damage weakly relates to the global characteristics of buildings. For example, through a series of shaking table testing in which various levels of realistic seismic damage were reproduced for a high-rise steel building specimen at the E-Defense facility in Japan, Ji et al. [9] demonstrated that the natural frequencies of the specimen decreased by $4.1 \%, 5.4 \%$, and $11.9 \%$ on average for three damage levels respectively, while the mode shapes changed very little. The changes in the modal properties were largely influenced by cracks in concrete slabs and barely provided the accurate location and extent of seismic damage on individual steel members. Besides, through the same testing, Chung [10] reported large variations in seismic damage at beam-column connections at the same floor level that experienced nearly identical deformation.

As strain responses directly reflect the local information of the monitored structural members, damage detection based on strain responses has drawn extensive attention to the health monitoring of bridges, pipelines, and aircrafts in recent years. Li and $\mathrm{Wu}$ [11] and Hong et al. [12] utilized long-gauge fiber Bragg grating (FBG) sensors to measure the strain distribution throughout the full or critical areas of the Wayne bridge located in New Jersey in America under ambient excitation and identified the location and extent of localized damage. Razi et al. [13] reported a vibration-based damage detection strategy with strain information measured by lead zirconate titanate (PZT) sensors for detecting bolt loosening of pipeline's bolted flange joints in the oil and gas industry. Mujica et al. [14] located the position of impact damage on a section of a commercial aircraft wing flap using strain responses sensed by PIC 155 (i.e., a modified PZT material produced by PI Ceramic GmbH, Germany) piezoceramic sensors and a knowledgebased reasoning methodology. Nevertheless, due to the high costs for the installation and maintenance of the current tethered SHM systems, strain monitoring with a high-density measurement system has been thought to be uneconomic and impractical in the building engineering community. More importantly, as buildings are always excited by ambient vibrations with large randomness, finding an effective strain-based damage index with independency of external excitations for localized damage is a great challenge. Thus, research on the localized damage detection of buildings with strain responses is very limited at present.

With the emergence of wireless sensing technology [15-17] and high-sensitivity piezoelectric strain sensors [18], which have great potential to develop economical dense-array sensing systems, Kurata et al. [19] developed a damage index based on the dynamic strain responses of steel beams and verified its performance using a five-story steel frame testbed. Nonetheless, the research only includes preliminary studies on damage detection and needs further generalization in theoretical formulations and experimental studies for developing a damage quantification 
93

94

95

96

97

98

99

100

101

102

103

104

105

106

107

108

109

110

111

112

113

114

115

116

117

118

119

120

121

122

123

124

125

126

127

128

129

130

131

132

133

134 methodology using dynamic strain information. This paper presents a general formulation of the damage index with dynamic strain responses. It is followed by studies on the influence of sensor location and input excitation on the damage index using a nine-story steel moment-resisting frame designed for the SAC project. To enable the quantification of local damage besides damage detection, the empirical curve for the relationship between the damage index and the reduction in bending stiffness at a fractured section was obtained for different sensor locations. Finally, the general formulation and the results of numerical studies were verified through a series of ambient vibration tests and shaking table tests using a five-story steel frame testbed.

\section{DAMAGE INDEX FOR EVALUATING BEAM FRACTURE}

\subsection{Damage index based on changes of relative strain responses}

In steel moment-resisting frames, inclusion of fracture at beam-ends changes the amplitude of the bending strain responses at the damaged beams, which are primarily influenced by the reduction in the bending stiffness of the damaged beams. Thus, a comparative study of the bending strain responses of beams for undamaged and damaged frames, which are excited with small dynamic loads (e.g., ambient vibrations and minor earthquake ground motions), allows the evaluation of the extent of damage to beams. In addition, adopting the equivalent static force approach [20] can eliminate the influence of external excitations on damage evaluation analysis. This section reformulates the strain-based damage evaluation methodology with bending strain responses, which was originally formulated with bending moment responses of beams in [19].

When an $n$-story steel moment-resisting frame is subject to lateral dynamic loads such as ground motions, at any instant of time $t$, the equivalent static forces $F(t)=\left[f_{1}(t), f_{2}(t), \cdots, f_{i}(t), \cdots, f_{n-1}(t), f_{n}(t)\right]^{T}$ act on the frame as external forces, as illustrated in

Figure 1. Suppose the frame vibrates linearly under small-amplitude excitations, at instant of time $t$, a bending strain response measured at any beam can be formulated as

$$
\varepsilon(t)=\alpha_{1} f_{1}(t)+\alpha_{2} f_{2}(t)+\cdots+\alpha_{i} f_{i}(t)+\cdots+\alpha_{n-1} f_{n-1}(t)+\alpha_{n} f_{n}(t)=\sum_{i=1}^{n} \alpha_{i} f_{i}(t),
$$

where $\alpha_{i}(i=1, \ldots, n)$ is an influence factor of the equivalent static force $f_{i}(t)$, which relates only to the structural properties (i.e., material and geometric properties) and is unaffected by the characteristics of external excitations. Since the equivalent static forces associated with the $j$ th mode vibration are

$$
F_{j}(t)=\omega_{j}^{2} \mathbf{M} \Phi_{j} q_{j}(t)
$$

the bending strain response of the beam associated with the $j$ th mode is expressed as

$$
\varepsilon_{j}(t)=\omega_{j}^{2} q_{j}(t) \sum_{i=1}^{n} \alpha_{i} m_{i} \phi_{i j},
$$


135

136

137

138

where $\omega_{j}$ and $\Phi_{j}=\left[\phi_{1 j}, \phi_{2 j}, \cdots, \phi_{i j}, \cdots, \phi_{n-1 j}, \phi_{n j}\right]^{T}$ are the $j$ th modal frequency and mode shape; $\mathbf{M}=\operatorname{diag}\left(m_{1}, m_{2}, \cdots, m_{i}, \cdots, m_{n-1}, m_{n}\right)$ is the mass matrix for the frame in which $m_{i}(i=1, \ldots, n)$ is the lumped mass of the floor; and $q_{j}(t)$ is the modal coordinate for the $j$ th mode [20].

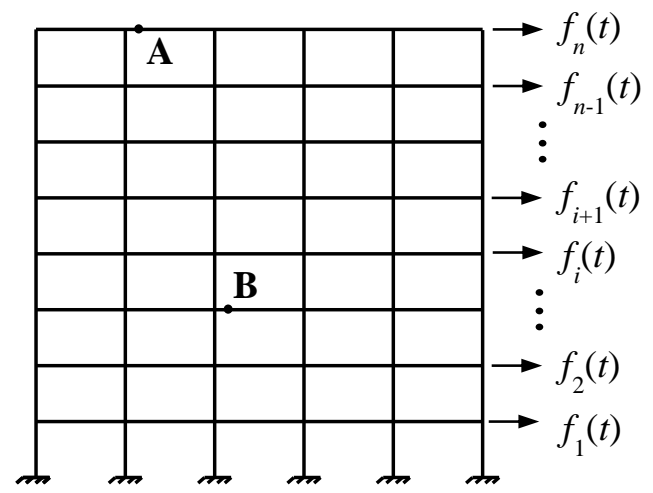

Figure 1. $n$-story steel moment-resisting frame under equivalent static forces.

Now consider the ratio of the bending strain responses of beams associated with the $j$ th mode at any two different positions $\mathrm{A}$ and $\mathrm{B}$ (position $\mathrm{A}$ as a reference point) at any instant time $t$ :

The obtained ratio of the bending strain responses only relates to the structural properties of the frame, and has no relationship with external excitations. Reference point A needs to be located in the undamaged floor for evaluating the beam damage near point B. A floor with small deformation (e.g., the roof) is recommended for the reference point where the concrete slabs and beams at the floor remain undamaged. While not quantitatively examined, slight damage (i.e., minor cracks in the concrete slabs and yielding of the beams) is deemed to have little influence on the bending strain at the reference point.

In practice, errors or uncertainties in data measurement and signal processing (e.g., timesynchronization errors, outliers, and distortion with filters) affect the instantaneous bending stain responses associated with the $j$ th mode vibration, which are estimated as a peak in the frequency domain response, especially when the signal-to-noise $(\mathrm{S} / \mathrm{N})$ ratio is not large with smallamplitude excitations. Therefore, given the bending strain time histories with a time interval of $\Delta t$ (each including $k$ points) at two positions $\mathrm{A}$ and $\mathrm{B}$, the ratio of the root mean square (RMS) of these two time histories under the $j$ th mode vibration is considered as 


$$
\frac{\left(\varepsilon_{j}^{B}\right)_{R M S}}{\left(\varepsilon_{j}^{A}\right)_{R M S}}=\sqrt{\frac{\frac{1}{k} \sum_{p=0}^{p=k-1}\left[\varepsilon_{j}^{B}(p \Delta t)\right]^{2}}{\frac{1}{k} \sum_{p=0}^{p=k-1}\left[\varepsilon_{j}^{A}(p \Delta t)\right]^{2}}}=\sqrt{\frac{\frac{1}{k}\left(\omega_{j}^{2} \sum_{i=1}^{n} \alpha_{i}^{B} m_{i} \phi_{i j}\right)^{2} \sum_{p=0}^{p=k-1}\left[q_{j}(p \Delta t)\right]^{2}}{\frac{1}{k}\left(\omega_{j}^{2} \sum_{i=1}^{n} \alpha_{i}^{A} m_{i} \phi_{i j}\right)^{2} \sum_{p=0}^{p=k-1}\left[q_{j}(p \Delta t)\right]^{2}}}=\frac{\sum_{i=1}^{n} \alpha_{i}^{B} m_{i} \phi_{i j}}{\sum_{i=1}^{n} \alpha_{i}^{A} m_{i} \phi_{i j}}
$$

The RMS ratio for the two bending strain time histories in Equation (5) equals the instantaneous relative bending strain in Equation (4) if there are no errors or uncertainties.

Two strain sensors S1 and S2 are placed on the bottom flanges of beams at positions A and B in Figure 1, respectively, to detect seismic damage at beam-end near position B. S1 is used as a reference sensor, which is sufficiently far from the damaged beams in the frame and unaffected by the damage. $\mathrm{S} 2$ is near the damage as a detecting sensor. In the undamaged condition, the relative RMS value of the bending strain time histories at the two sensors S1 and S2 associated with the $j$ th mode is expressed as

$$
R_{j}=\frac{\left(\varepsilon_{j}^{S 2}\right)_{R M S}}{\left(\varepsilon_{j}^{S 1}\right)_{R M S}}=\frac{\sum_{i=1}^{n} \alpha_{i}^{S 2} m_{i} \phi_{i j}}{\sum_{i=1}^{n} \alpha_{i}^{S 1} m_{i} \phi_{i j}}
$$

while under the damaged condition, it is expressed as

$$
R_{j}^{d}=\frac{\left(\bar{\varepsilon}_{j}^{S 2}\right)_{R M S}}{\left(\bar{\varepsilon}_{j}^{S 1}\right)_{R M S}}=\frac{\sum_{i=1}^{n} \bar{\alpha}_{i}^{S 2} m_{i} \bar{\phi}_{i j}}{\sum_{i=1}^{n} \bar{\alpha}_{i}^{S 1} m_{i} \bar{\phi}_{i j}},
$$

where the variables with top bars are for the damaged condition. Finally, the damage index $D I$ based on the bending strain responses of beams for detecting seismic damage on beams in steel moment-resisting frames can be defined as follows

$$
D I=\frac{R_{j}^{d}-R_{j}}{R_{j}} \times 100 \% .
$$

where if $R_{j}^{d}=R_{j}$, i.e., no damage , $D I$ is 0 ; if $R_{j}^{d}=0$, i.e., complete fracture, $D I$ is $-100 \%$.

Note that fracture at beam-ends has two influential factors on the bending strain responses measured by S2: (1) the bending strain decreases because of the reduction in the bending moment resisted by the damaged beam; and (2) the bending strain is affected by local strain redistribution around the fractured section. If sensor S2 is located in the region unaffected by the local strain redistribution, $D I$ is proportional to the reduction of the bending moment.

\subsection{Signal processing for damage estimation}


193

194

195

196

197

198

199

200

201

202

203

204

205

206

207

208

209

210

211

212

213

214

215

216

217

218

219

220

221

222

223

224

225

Figure 2 shows a step-by-step procedure for calculating the damage index $D I$. First, raw dynamic strain data of steel beams is preprocessed with data cleaning techniques (e.g., the removal of drifts and false points). Second, one mode of the steel moment-resisting frame is selected and the strain responses associated with the selected mode are extracted using band-pass filters. Third, the RMS values of the filtered strain data are calculated and then normalized by the RMS value of a reference position. Finally, damage information (existence, location, and extent) is extracted from the damage index DI calculated in Equation (8) at each detecting sensor.

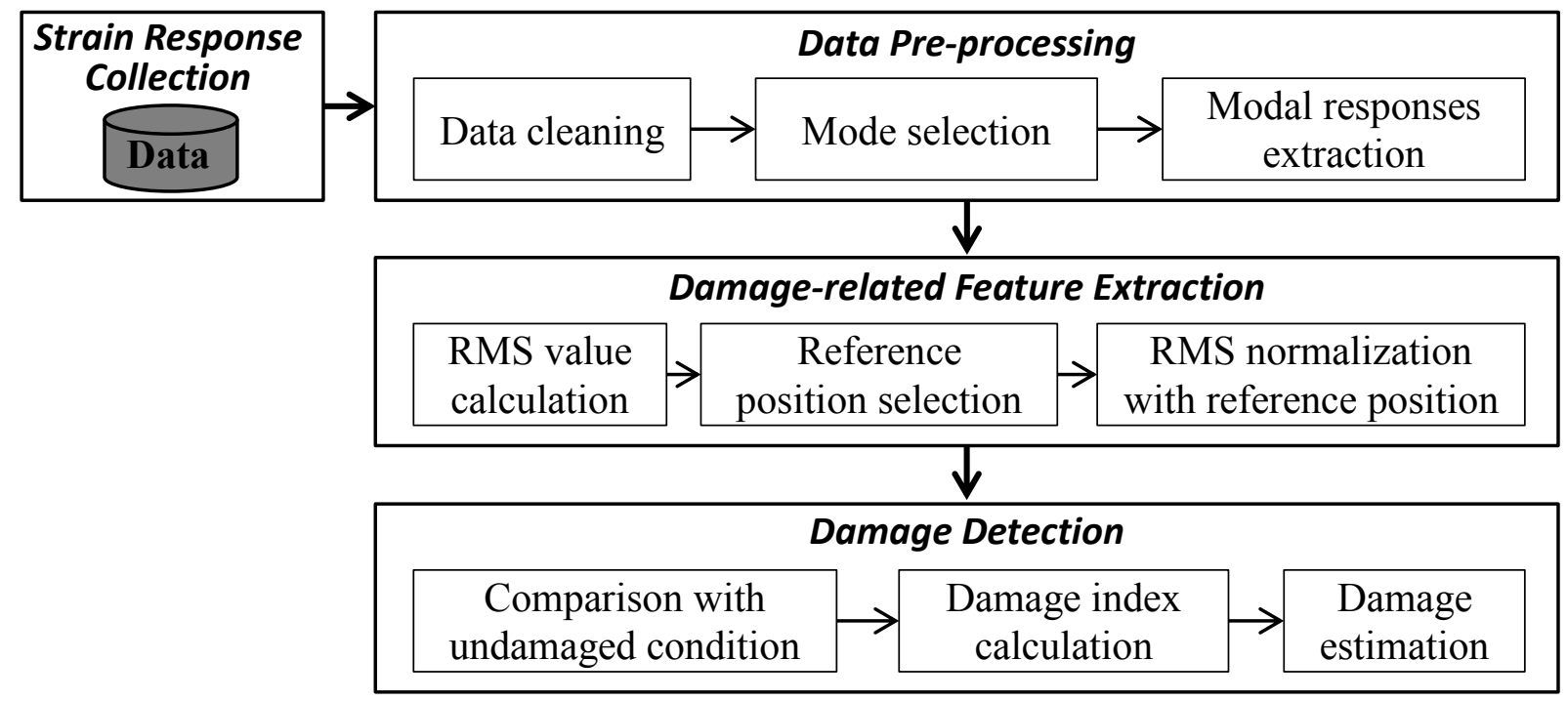

Figure 2. Procedure of damage evaluation.

\section{NUMERICAL ANALYSIS WITH A NINE-STORY STEEL MOMENT-RESISTING FRAME}

\subsection{Nine-story building model}

The effectiveness of the presented damage index $D I$ in evaluating the damage extent of seismic fracture on steel beams was verified through a numerical case study using the LA pre-Northridge nine-story building intensively studied in the SAC steel project [21]. The nine-story building represents typical medium-rise buildings designed according to the pre-Northridge design practice in Los Angeles, California. The building is $45.73 \mathrm{~m}$ by $45.73 \mathrm{~m}$ in plan, and $37.19 \mathrm{~m}$ in elevation (see Figure 3). Each bay spans $9.15 \mathrm{~m}$ in both the N-S and E-W directions. The lateral load-resisting system of the building comprises four perimeter steel moment-resisting frames. The interior bays of the structure contain gravity frames with composite floors. The wide flange columns of the moment-resisting frames are made from $345 \mathrm{MPa}$ steel. The column bases are modeled as pin connections. The horizontal displacement of the structure at ground level is assumed to be restrained. The floor system consists of wide flange beams made of $248 \mathrm{MPa}$ steel acting compositely with floor slabs. Typical beam sizes are W36x160 (with $I_{\mathrm{x}}$ of $4.062 \times 10^{9}$ $\mathrm{mm}^{4}$ ) from the ground to the third floors, W36x135 (with $I_{\mathrm{x}}$ of $3.247 \times 10^{9} \mathrm{~mm}^{4}$ ) from the fourth to seventh floors, and smaller beam sizes for the upper levels. The inertial effects of each floor are assumed to be evenly carried by each perimeter moment-resisting frame through the floor system. Hence, each frame resists one half of the seismic mass. The seismic mass of the ground 
level is $9.65 \times 10^{5} \mathrm{~kg}$, for the second floor is $1.01 \times 10^{6} \mathrm{~kg}$, for the third through ninth floors is $9.89 \times 10^{5} \mathrm{~kg}$, and for the tenth floor is $1.07 \times 10^{6} \mathrm{~kg}$.

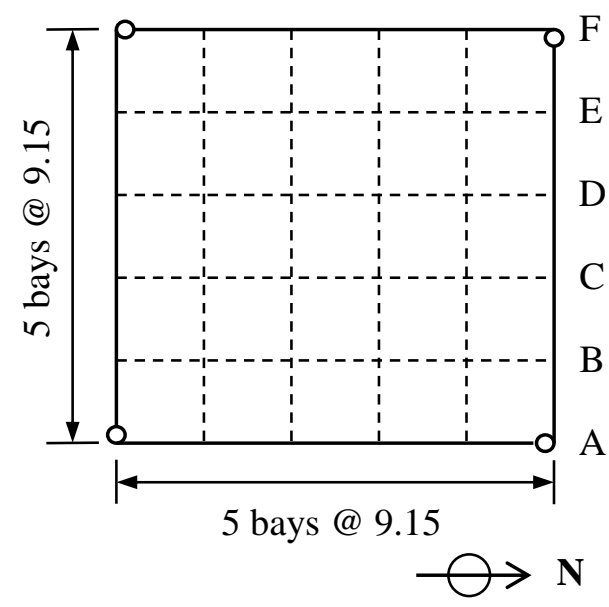

(a)

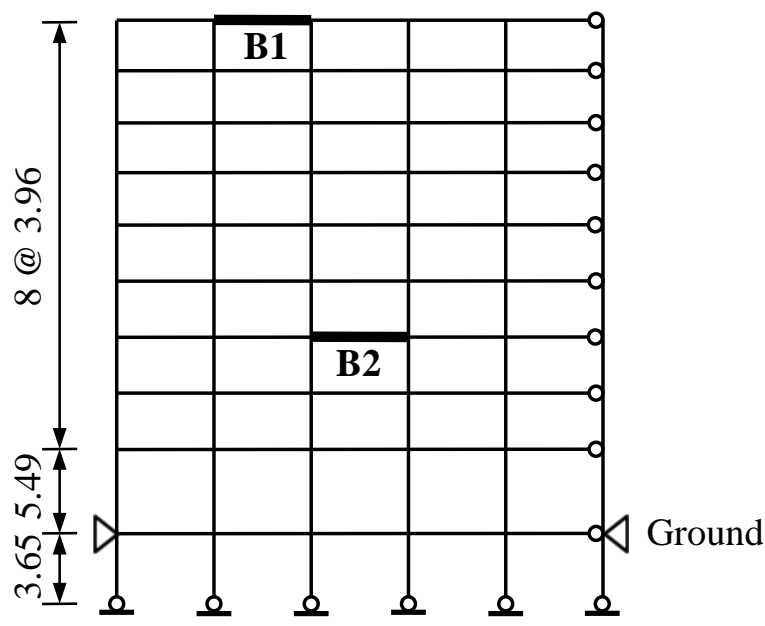

(b)

Figure 3. SAC nine-story building (unit: m): (a) building plan; (b) frame A elevation.

\subsection{Numerical simulation model}

The numerical study was conducted using the finite element (FE) analysis software, Marc [22]. Seismic fracture on one beam with various levels of damage extent was considered to verify the effectiveness of the presented damage index. The relation between the damage index and the location of strain sensors on a beam was also studied. As most seismic-induced beam fractures begin at the toe of the weld access hole and extend to the web, the beam fracture was simulated by cutting the bottom flange and/or web near the column surface at the left end of beam B2 (Figure 4). The length of the cut was one percent of the beam length. There were seven damage patterns for beam seismic fracture simulation, as listed in Table 1. DP1 to DP3 simulated fracture at one side of the bottom flange, where the decreases of the bending stiffness $E I_{x}$ at the cut section were smaller than $22 \%$. DP4 simulated the entire bottom flange fracture, in which the bending stiffness $E I_{x}$ at the cut section decreased by $49 \%$. Severe fracture damage extending from the bottom flange to the web was simulated in DP5 to DP7 with the reduction of more than $75 \%$ in the bending stiffness $E I_{x}$ at the cut section. In the finite element model, two beams B1 and B2 were modeled with shell elements, and other beams and columns were modeled with beam elements (Figure 5). The nodes of shell elements at the beam-ends were connected to the nodes of beam elements with rigid links.

The measurement locations of the bending strain responses of beams are shown in Figure 6 . $\mathrm{S}_{r e f}$ as a reference sensor was set on the left end of beam B1 at the top floor where was considered to be far from the damage location (Figure 6(a)). In practice, several beams with the least damage probability may be selected to set reference sensors. S1 to $\mathrm{S} 8$ as detecting sensors were on one side of the bottom flange of beam B2 at intervals of $l$ or $2 l\left(l=0.2 d_{2}\right.$, where $d_{2}$ is the depth of beam B2) from the column surface (Figure 6(b)). The frame was excited with two excitations (Figure 7): (1) a white noise (WN); and (2) an earthquake ground motion (EM). 


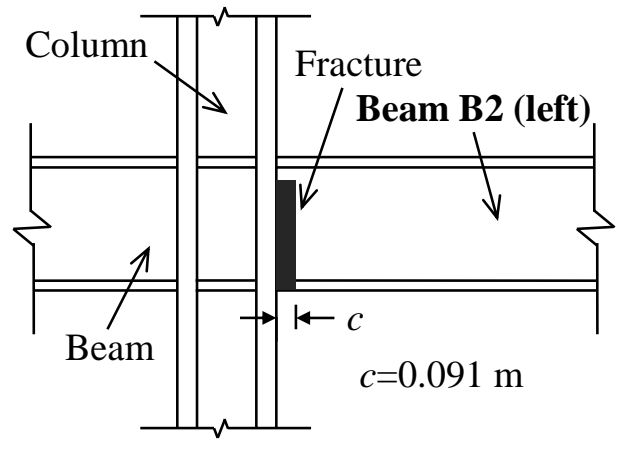

Figure 4. Simulated fracture.

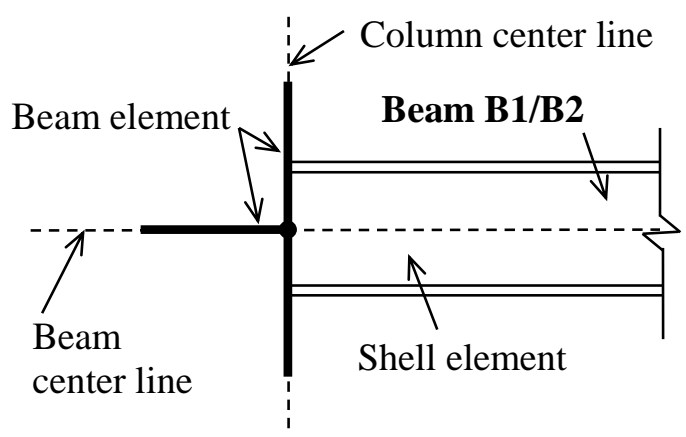

Figure 5. Connection between beam elements and shell elements.
257

258

Cross-section

Damage pattern Undamaged

Cross-section

\begin{tabular}{cc}
$E I_{x}$ reduction $(\%)$ & 0 \\
\hline Damage pattern & DP5 \\
Cross-section &
\end{tabular}

$E I_{x}$ reduction $(\%)$

76.1

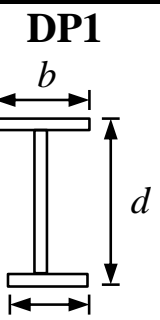

$5 b / 6$

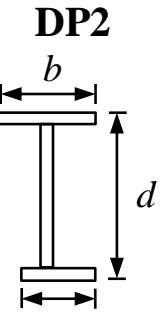

$2 b / 3$

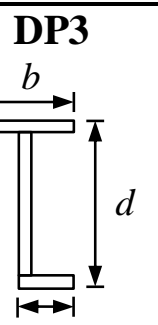

$b / 2$

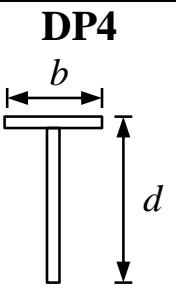

49.1

259

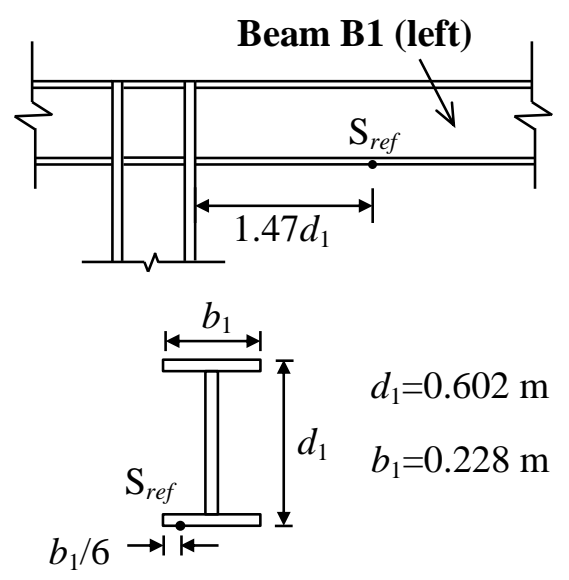

(a)

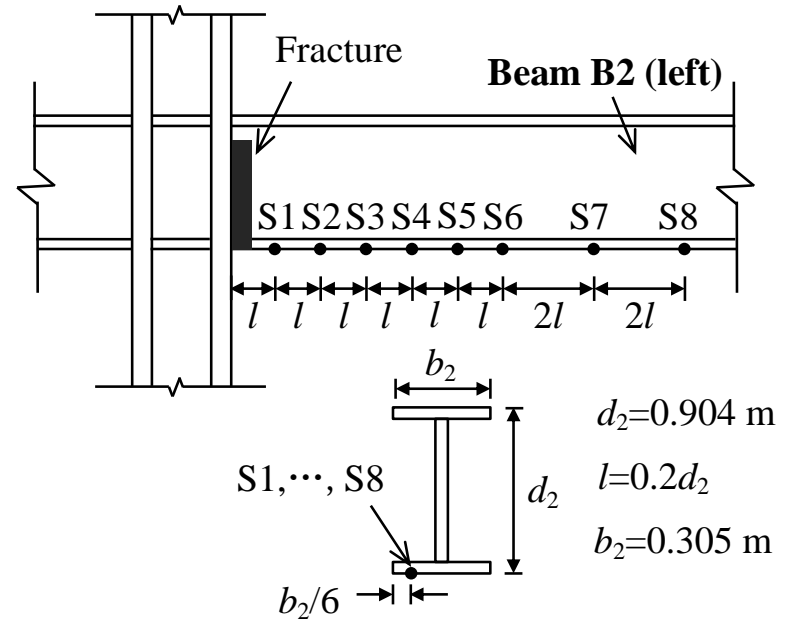

(b)

Figure 6. Strain output location: (a) reference sensor; (b) detecting sensors. 


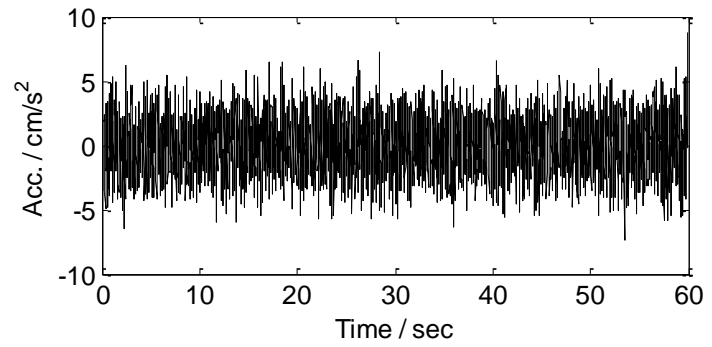

(a)

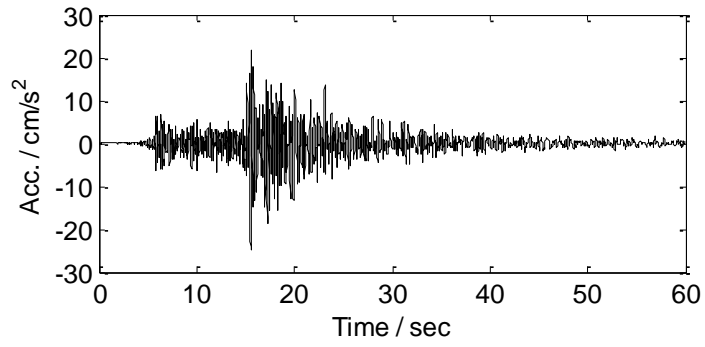

(b)
262

263

264

265

266

267

268

269

270

271

272

273

274

275

276

277

278

279

280

281

Figure 7. Input excitations: (a) white noise; (b) earthquake ground motion.

\subsection{Data preprocessing}

The first four natural frequencies of the undamaged model of the nine-story frame were 0.432 , $1.150,1.987$, and $2.988 \mathrm{~Hz}$, which were consistent with those reported previously [23]. For reference, the inclusion of the severest damage condition at Beam B2 (DP7 with a reduction of 99\% in the bending stiffness $E I_{x}$ at the cut section) reduced the first four natural frequencies to 0.429 , $1.150,1.980$, and $2.963 \mathrm{~Hz}$, where the largest change in these frequencies was only $0.9 \%$. Note that damage to a critical member that assures the overall stability of the frame, such as a column, can lead to a more significant change in the natural frequency.

Figure 8 shows the bending strain responses and their power spectral densities of the reference sensor $\mathrm{S}_{\text {ref }}$ at the undamaged condition. The power spectral densities (PSD) for both excitations indicate that the responses of the frame were mainly dominated by the first three modes. Therefore, the bending strain responses associated with the first three modes were respectively used to calculate the damage index $D I$. The strain responses associated with each mode were obtained using band-pass filters on raw strain responses. Considering the slight changes in the natural frequencies with the inclusion of damage, the bandwidth of the band-pass filter was set to include $\pm 10 \%$ of each natural frequency. Thus, the band-pass filters were $0.38-0.48,1.04-1.27$, and $1.79-2.19 \mathrm{~Hz}$ for the first three modes.
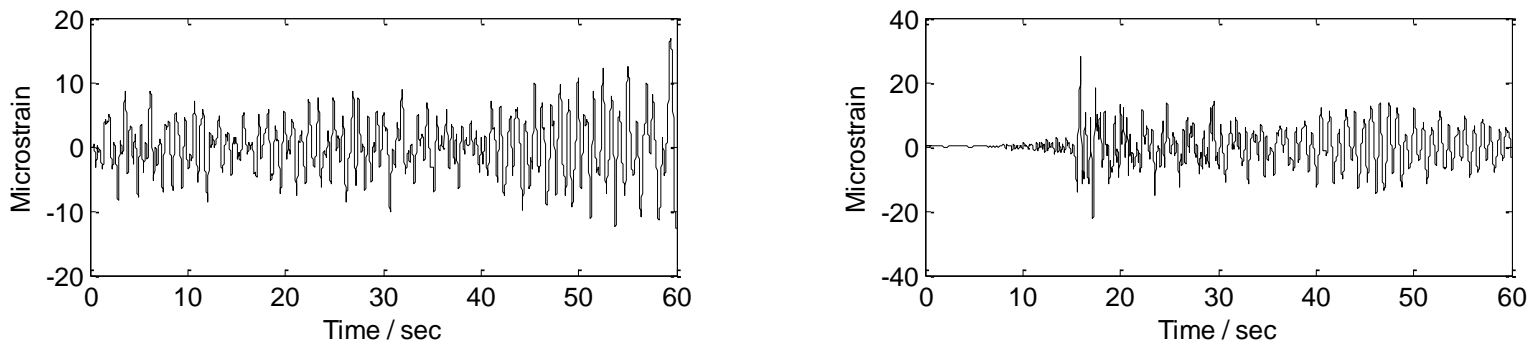

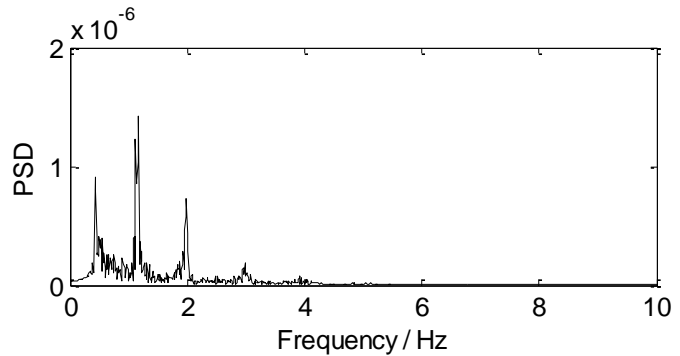

(a)

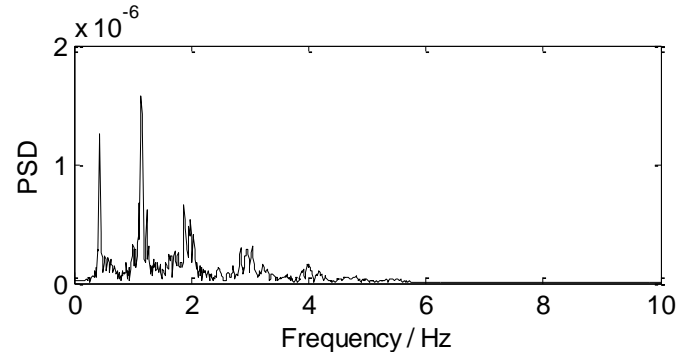

(b)
282 283

Figure 8. Bending strain responses at reference sensor $\mathrm{S}_{r e f}$ : (a) white noise; (b) earthquake ground motion. 
284

285

286

287

288

289

290

291

292

293

294

295

296

297

298

299

300

301

\subsection{Simulation results}

\subsubsection{Independency on excitations and modes}

The variations in the ratio of RMS values of the bending strain responses were studied for the undamaged condition. Figure 9 shows the ratios of the first mode for each detecting sensor (i.e., $\mathrm{S} 1$ to $\mathrm{S} 8$ ) relative to the reference sensor $\mathrm{S}_{\text {ref. }}$. The values of the ratio were the largest at $\mathrm{S} 1$ and the smallest at S8, and proportional to the bending moments sustained at each beam section. When two excitations were compared using modal analysis (i.e., no need to extract the modal strain responses from the time histories), the difference was up to $3.8 \%$ for the white noise, and $0.05 \%$ for the earthquake ground motion, which confirmed the independence of the extracted ratio of RMS values on external excitation as indicated by Equation (5) of the preceding theoretical formulation. Note that the differences arise from errors in the extraction of the modal strain responses with band-pass filters. Compared to the white noise, the earthquake ground motion that generated a relatively large-amplitude strain response (see Figure 8) had a small discrepancy.

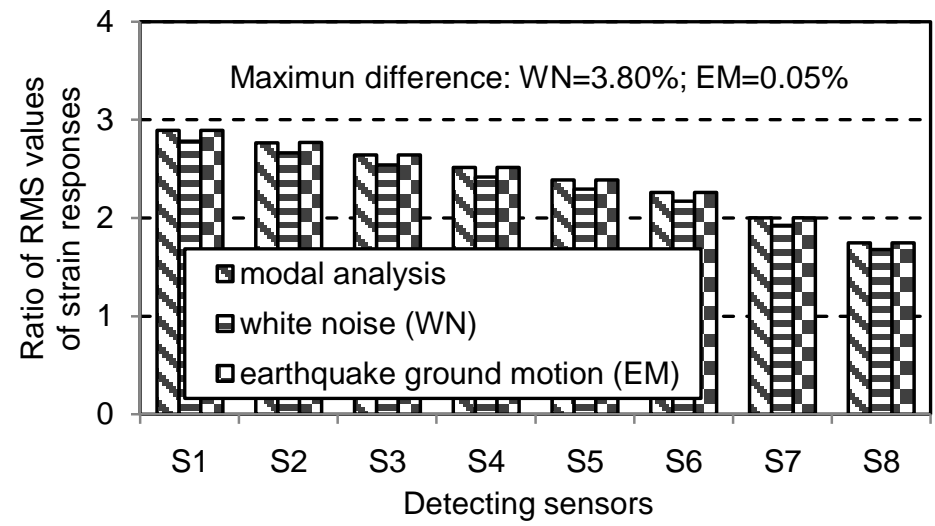

Figure 9. Ratio of RMS values for different detecting sensors and excitations.

Next, the selection of reference values and modes were studied. Figure 10 shows the damage index DI at sensor S6 for two different selections of the reference values under the undamaged condition.

Reference 1: Ideal case where the same excitation was used for undamaged and damaged conditions.

Reference 2: Practical case where ambient vibration assumed to be white noise was used to prepare the reference values under the undamaged condition.

The horizontal axes of the plots are the reduction of the bending stiffness at the fractured section and the vertical axes are the damage index DI calculated with Equation (8). As the bending stiffness $E I_{x}$ decreases, the damage index drops from 0 to $-100 \%$. When reference 1 was applied, the damage indices were identical for different excitations and selected modes. In contrast, when reference 2 was applied, while the damage indices extracted from strain responses under white noise were identical for the first three modes, the damage indices extracted from the strain responses under earthquake ground motion contained errors (as the errors significantly exceeded the real damage index at DP1 to DP3, the damage index takes positive values that are 
false-negative). This is because the errors in the extraction of modal responses with band-pass filters under the undamaged and damaged conditions were not identically offset. The maximum error of the damage indices extracted from the first two modes was not greater than $4 \%$, while that for the third mode without a clear fundamental peak (see Figure 8(b)) exceeded 9\%. In Figure $8(\mathrm{~b})$, the power ratio of the fundamental peak to the irrelevant noise (i.e., responses not related to the natural vibration modes) in the filter bandwidth is $64.1 \mathrm{~dB}$ for the first mode, 2.1 $\mathrm{dB}$ for the second mode, and $0.3 \mathrm{~dB}$ for the third mode. In summary, the dominant modes with a higher peak in the power spectral density are more suitable for computing the damage index.

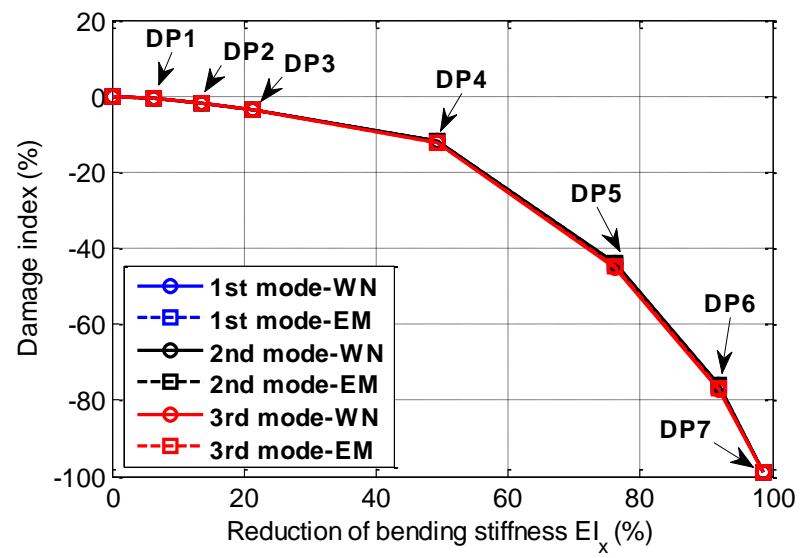

(a)

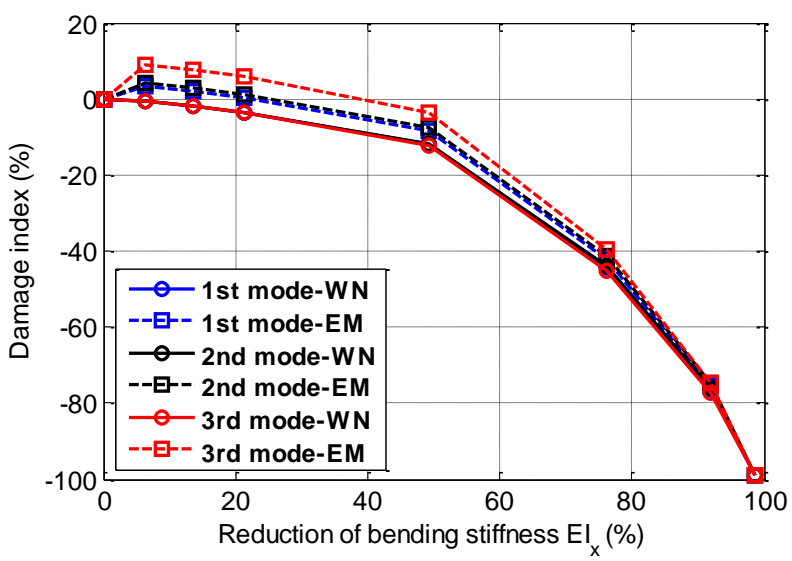

(b)

Figure 10. Damage index DI at detecting sensor S6: (a) with the first selection of reference values; (b) with the second selection of reference values.

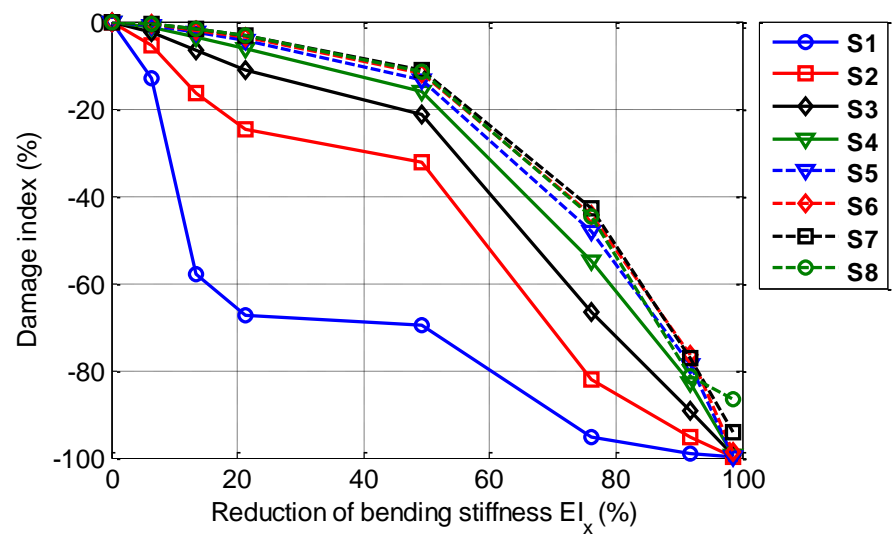

Figure 11. Damage index at all detecting sensors S1 to S8.

\subsubsection{Influence of sensor location}

As mentioned in section 2, strain responses near beam-ends are influenced by local strain redistributions around fractures. Thus, the transition of the damage index along the beam axis was studied. According to the finding in the preceding section, the damage index was extracted from the first mode vibration under white noise excitation and with reference 1 . Figure 11 shows the damage index for all detecting sensors S1 to S8. The damage index was affected by the local strain redistribution at $\mathrm{S} 1$ to $\mathrm{S} 5$ (i.e., the region that is less than $1.2 d$ from the column surface). In contrast, the damage index was almost identical at S6 to S8 (i.e., the region that is more than $1.2 d$ 
from the column surface), which indicates that the influence of the local strain redistribution is negligible and the values of the damage index are related primarily to the extent of moment redistribution induced by the damage.

Practically speaking, as the beam-end region within one beam depth from column surfaces may sustain large plastic deformation during strong earthquake events, detecting sensors had better be placed outside that region to be fully functional after the events. Thereby, it is recommended to place damage-detecting sensors at a distance of larger than $1.2 d$ from the column surface, and to estimate the reduction in the bending stiffness at the fractured section with the empirical curve shown in Figure 11.

\section{EXPERIMENTAL VERIFICATION USING A FIVE-STORY STEEL FRAME TESTBED}

A series of vibration tests was conducted to experimentally verify the presented damage index. A quarter-scale five-story steel moment-resisting frame constructed in the structural laboratory at the Disaster Prevention Research Institute (DPRI), Kyoto University, was used as the testbed frame. In the tests, a wireless strain sensing system was used to measure the bending strain responses of steel beams.

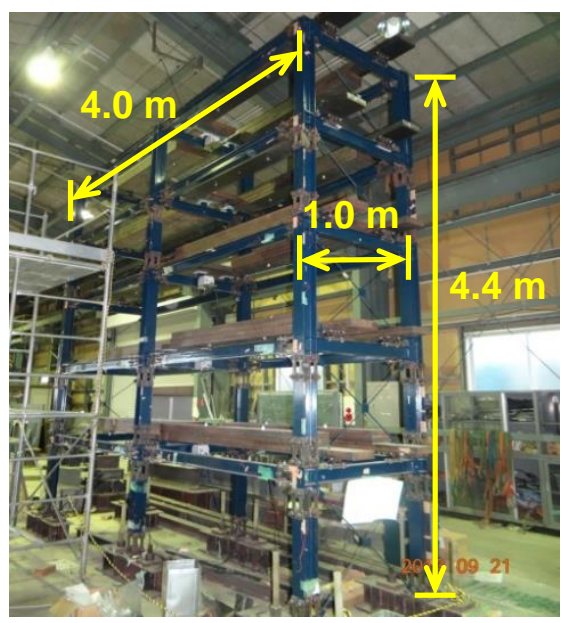

(a)

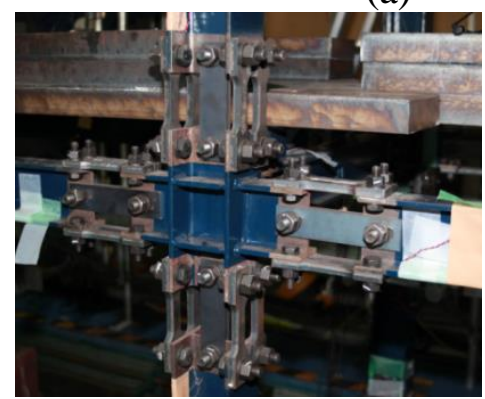

(c)

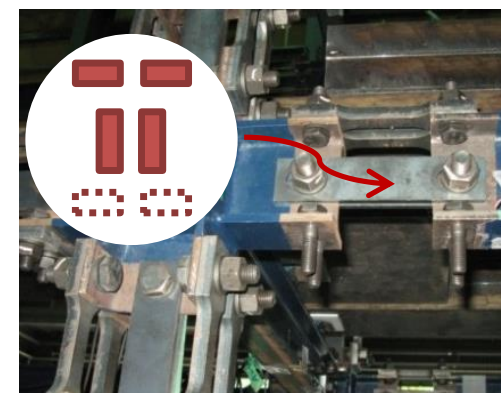

(d)

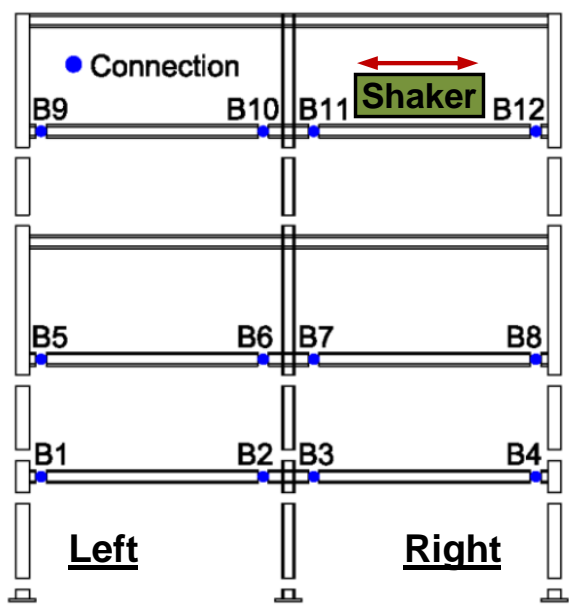

(b)

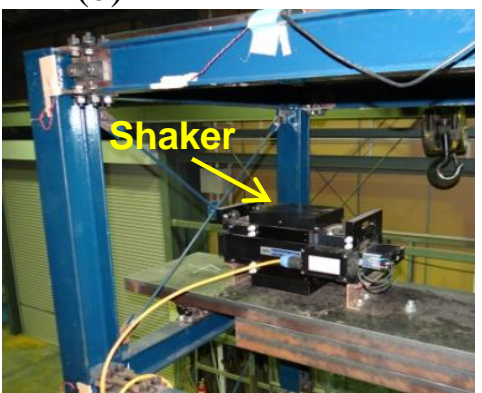

(e)

Figure 12. Steel frame testbed: (a) overview; (b) beam removable connections; (c) beam-column connection; (d) simulated damage; (e) modal shaker. 
367

The overall dimensions of the steel frame were $1.0 \times 4.0 \times 4.4 \mathrm{~m}$ (Figure 12(a)). The plan of the frame was one bay by two bays. At the second, third and fifth floors, beams in the longitudinal direction and columns were connected to joints using removable steel connections (four links at the flanges and one pair of links at the web) (Figure 12(b and c)). By removing the links, fracture damage was simulated (see Figure 12(d)). The five-story steel frame testbed was described in detail by Kurata et al. [19].

\subsection{Damage patterns}

Considering typical fracture patterns of wide flange beams in steel buildings, which initiated from the tail of weld access holes at bottom flanges, two types of fracture damage, i.e., fracture of the bottom flange and web, were simulated. Figure 13 illustrates the cross-section of the removable connection and two levels of simulated fracture damage. In damage level 1 (L1), two links of the bottom flange of the connection were removed. In damage level 2 (L2), both bottom flange and web links were removed. As summarized in Table 2, the reduction in the bending stiffness about the strong axis of the beam section was $68.5 \%$ for damage L1 and $99.8 \%$ for damage L2.
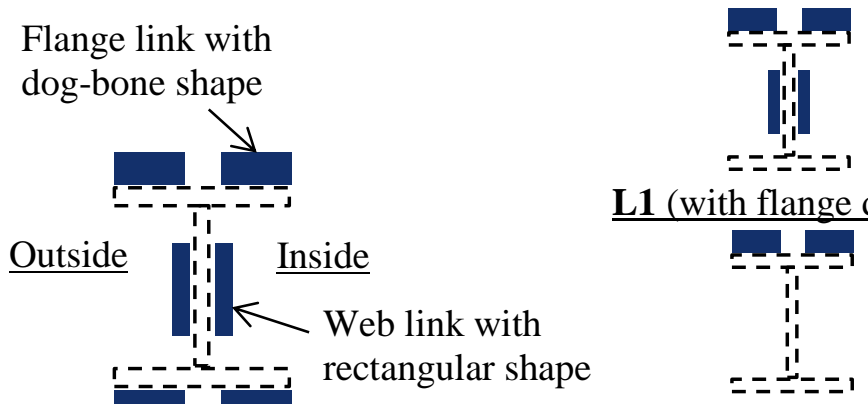

$\underline{\text { L1 (with flange damage) }}$

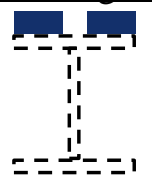

$\underline{\mathbf{L 2}}$ (with flange and web damage)

Figure 13. Damage patterns.

Table 2. Damage categories.

\begin{tabular}{ccr}
\hline Damage category & Description & Reduction of $E I_{x}(\%)$ \\
\hline L1 & All links of bottom flange are removed & 68.5 \\
L2 & All links of bottom flange and web are removed & 99.8 \\
\hline
\end{tabular}

\subsection{Damage cases}

In the testbed frame, there are twelve removable beam connections, connections B1 to B12 (see Figure 12(b)), in each longitudinal frame. Three different types of vibration test (i.e., Test 1 to Test 3 ) including a total of ten damage cases were conducted to evaluate the performance of the damage index and to verify the findings of the previous numerical simulations on input excitations and sensor locations.

Test 1: Independency of the damage index on external excitations and vibration modes was verified with a shaking table at the DPRI as excitation source. Damage L1 and L2 were simulated at connection B2 near the inner joint of the second floor. 
400

401

402

403

404

405

406

407

408

409

410

411

412

413

414

415

416

417

Test 2: Influence of sensor location on the damage index was examined with a modal shaker as excitation source. Damage L1 and L2 were simulated at connection B1 near the exterior joint of the second floor.

Test 3: General applicability of the damage index was examined with a modal shaker as excitation source. Two levels of fracture damage, Damage L1 and L2, were simulated at three different connections B2, B6, and B10.

Test 4: Influence of neighboring damage on the damage index was studied with a modal shaker as excitation source. As beam seismic damage changes the moment distribution rather locally, only the influence of fracture damage at the closest beam-ends on the same floor level was considered.

Test 4 was conducted to obtain preliminary data for multiple damage condition; at this moment, the presented damage index does not explicitly consider the influence of neighboring damage and further study is required. Note that all the tests considered fracture damage only in one longitudinal frame, while another longitudinal frame remained intact. The inclusion of asymmetric damage may induce torsional vibrations of the frame but the influence on the lateral mode vibrations was found negligible.

Table 3. Damage cases.

\begin{tabular}{|c|c|c|c|c|c|c|c|}
\hline \multirow{3}{*}{ Test } & \multirow{3}{*}{$\begin{array}{c}\text { Damage } \\
\text { Case }\end{array}$} & \multicolumn{4}{|c|}{ Damage } & \multirow{3}{*}{ Targets } & \multirow{3}{*}{$\begin{array}{c}\text { Loading } \\
\text { system }\end{array}$} \\
\hline & & \multicolumn{2}{|c|}{ As detected } & \multicolumn{2}{|c|}{ Influence sources } & & \\
\hline & & Location & Category & Location & Category & & \\
\hline \multirow{3}{*}{ Test 1} & Undamaged & - & - & - & - & \multirow{3}{*}{$\begin{array}{l}\text { Independency } \\
\text { on excitations } \\
\text { and modes }\end{array}$} & \multirow{3}{*}{$\begin{array}{c}\text { Shaking } \\
\text { table }\end{array}$} \\
\hline & Case 1 & B2 & L1 & - & - & & \\
\hline & Case 2 & $\mathrm{~B} 2$ & L2 & - & - & & \\
\hline \multirow{2}{*}{ Test 2} & Case 3 & B1 & L1 & - & - & \multirow{2}{*}{$\begin{array}{c}\text { Influence of } \\
\text { sensor location }\end{array}$} & \multirow{2}{*}{$\begin{array}{l}\text { Modal } \\
\text { shaker }\end{array}$} \\
\hline & Case 4 & B1 & L2 & - & - & & \\
\hline \multirow{6}{*}{ Test 3} & Case 5 & B2 & L1 & - & - & \multirow{6}{*}{$\begin{array}{c}\text { General } \\
\text { applicability }\end{array}$} & \multirow{6}{*}{$\begin{array}{l}\text { Modal } \\
\text { shaker }\end{array}$} \\
\hline & Case 6 & B6 & L1 & - & - & & \\
\hline & Case 7 & B10 & L1 & - & - & & \\
\hline & Case 8 & $\mathrm{~B} 2$ & L2 & - & - & & \\
\hline & Case 9 & B6 & L2 & - & - & & \\
\hline & Case 10 & $\mathrm{~B} 10$ & L2 & - & - & & \\
\hline \multirow{7}{*}{ Test 4} & Case 11 & B3 & L1 & - & - & \multirow{7}{*}{$\begin{array}{c}\text { Influence of } \\
\text { neighboring } \\
\text { damage }\end{array}$} & \multirow{7}{*}{$\begin{array}{l}\text { Modal } \\
\text { shaker }\end{array}$} \\
\hline & Case 12 & B3 & L1 & B2 & L1 & & \\
\hline & Case 13 & B3 & L1 & B2 & L2 & & \\
\hline & Case 14 & B3 & L1 & B4 & L2 & & \\
\hline & Case 15 & B3 & L2 & - & - & & \\
\hline & Case 16 & B3 & L2 & B2 & L2 & & \\
\hline & Case 17 & B3 & L2 & B4 & L2 & & \\
\hline
\end{tabular}

418

\subsection{Excitations}

In Test 1, the steel frame was excited in the longitudinal direction by the shaking table at the DPRI, Kyoto University, with two small-amplitude excitations (Figure 14): (1) a white noise (WN) with a frequency range of 1 to $50 \mathrm{~Hz}$ and RMS of $2 \mathrm{~cm} / \mathrm{s}^{2}$; and (2) an small-amplitude earthquake ground motion (EM) with the maximum acceleration of $18 \mathrm{~cm} / \mathrm{s}^{2}$. In the undamaged 
425 frame, these excitations induced the top floor acceleration responses of 4.38 and $12.32 \mathrm{~cm} / \mathrm{s}^{2}$ in 426 RMS, respectively. In Tests 2, 3 and 4, the steel frame testbed was excited at the fifth floor using 427 a modal shaker (APS-113, APS Dynamics) firmly fixed to the steel mass plate (Figure 12(e)). 428 The steel frame was excited in the longitudinal direction using three excitations: (1) ambient 429 excitation (AmbE); (2) small-amplitude white noise with a frequency range of 1 to $50 \mathrm{~Hz}$ (WN1); and (3) relatively large-amplitude white noise with a frequency range of 1 to $50 \mathrm{~Hz}$ (WN2). In the structural laboratory where the testbed frame was located, ambient vibrations mainly caused by ground microtremor was around $0.49 \mathrm{~cm} / \mathrm{s}^{2}$ in RMS at the top floor. When the undamaged frame 435 was excited with two white noise excitations, the roof acceleration responses were 3.32 and 8.45 $\mathrm{cm} / \mathrm{s}^{2}$ in RMS for WN1 and WN2, respectively.

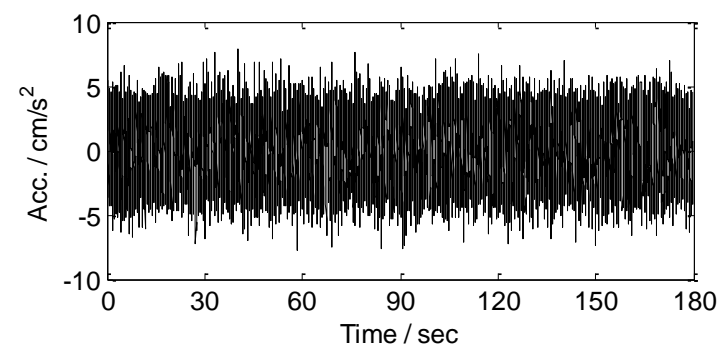

(a)

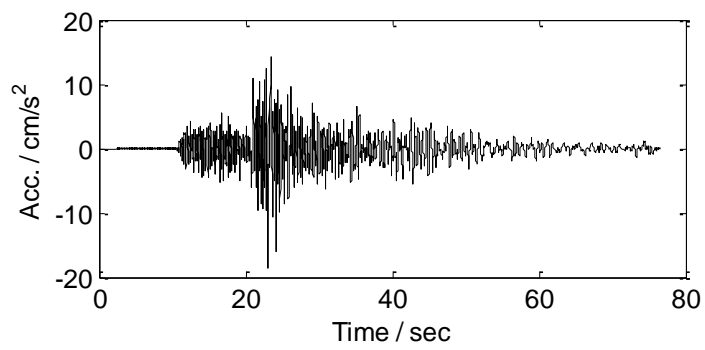

(b)

436 Figure 14. Input excitations for the shaking table: (a) white noise; (b) earthquake ground motion.

437
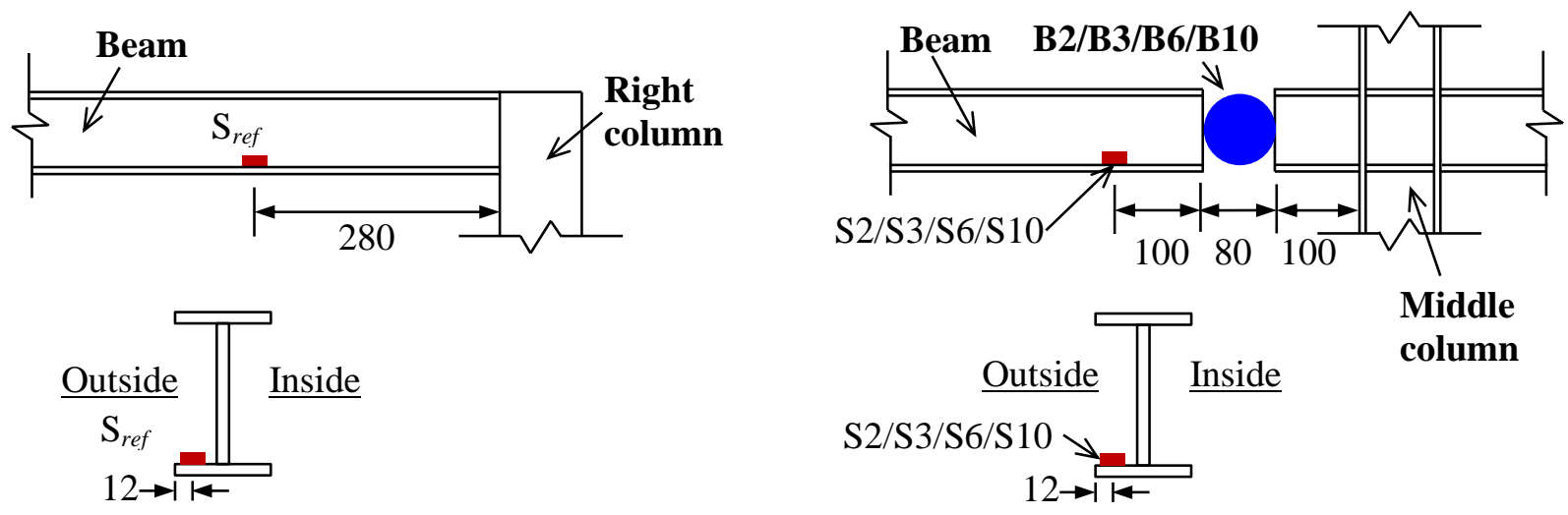

(a)
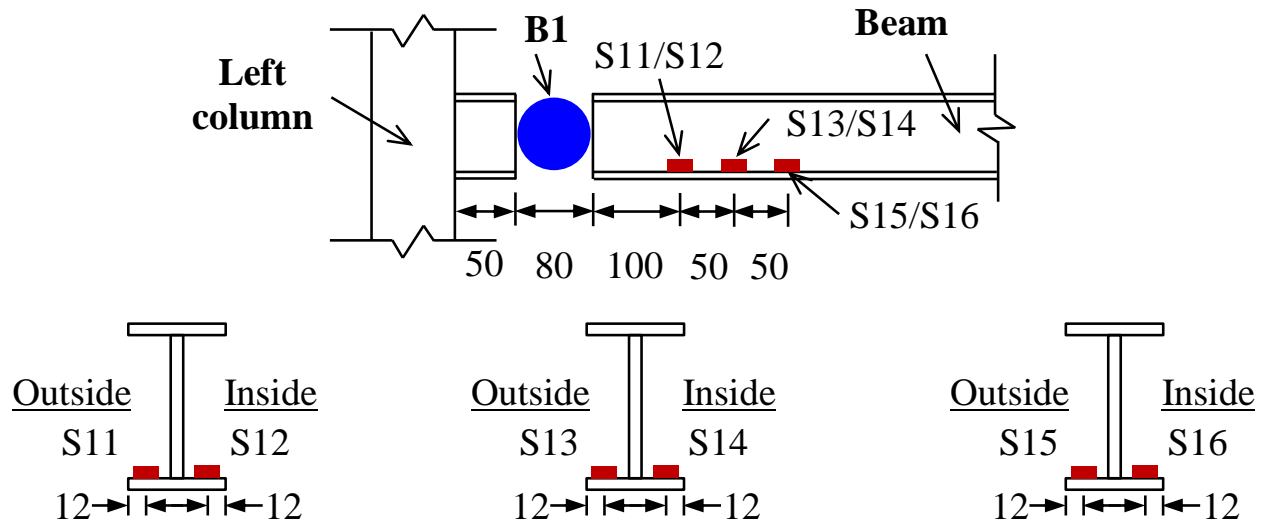

(c) 

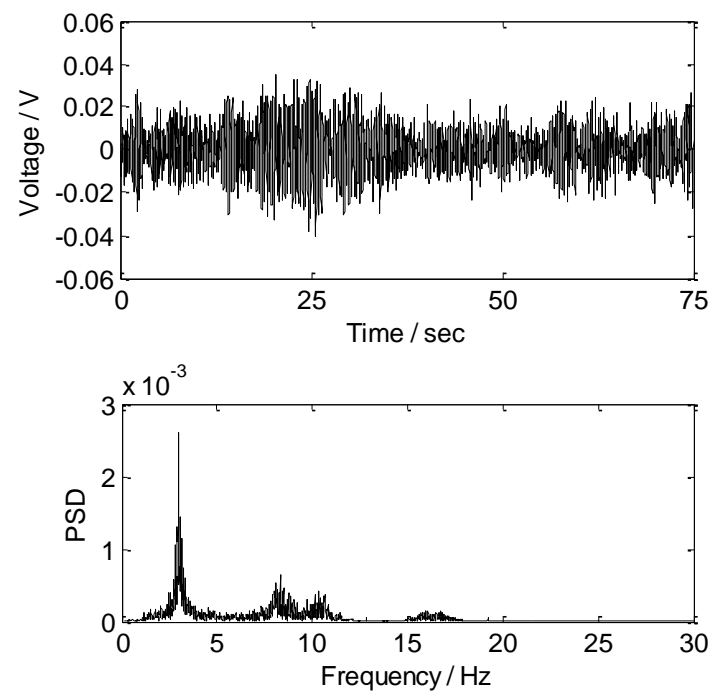

(a)

\subsection{Sensor location} the fractured section.
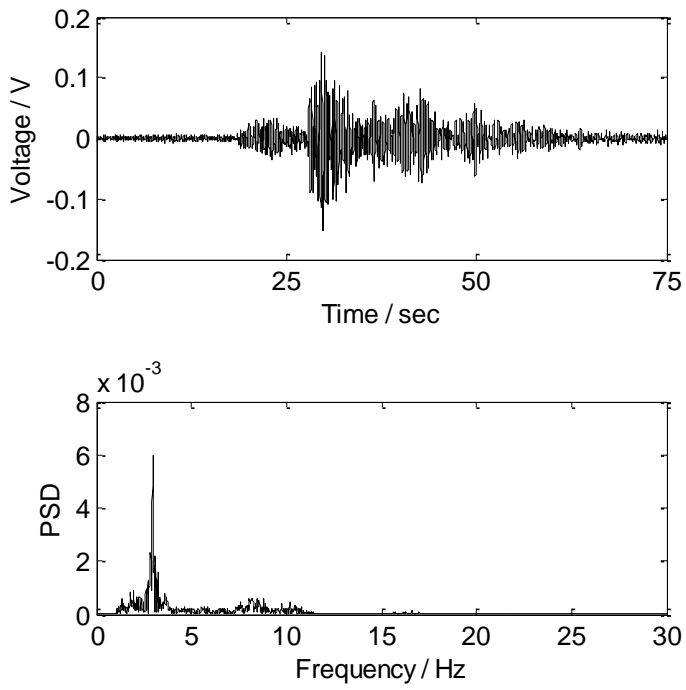

(b)

(c) sensors in Test 2 .

Polyvinylidene difluoride (PVDF) piezo films (DT1-028K/L, Measurement Specialties, USA) [24] interfaced with Narada wireless sensing units (Civionics, LLC, USA) [25] were used in the tests. In all tests, the reference sensor $S_{r e f}$ (Figure 15(a)) was placed at the top floor. In Tests 1, 3 and 4, detecting sensors were placed on one side of the beam bottom flange at $1.0 \mathrm{~d}$ (the beam depth $d$ is $100 \mathrm{~mm}$ ) away from the edge of the fracture, as illustrated in Figure 15(b). Sensors S2, S3, S6, and S10 were used to detect the simulated damage at connections B2, B3, B6, and B10 respectively. In Test 2, detecting sensors were attached on both sides of the beam bottom flange at $1.0 \mathrm{~d}, 1.5 \mathrm{~d}$, and $2.0 \mathrm{~d}$ away from the edge of the fracture to examine the influence of sensor location. Six sensors S11 to S16 used to detect the damage at connection B1 are shown in Figure 15(c). While not included in this paper, when the fracture progressed from the tail of the weld access hole asymmetrically about the beam axis (e.g., the fracture of half of the bottom flange), the amount of local strain redistribution differed at each side of the bottom flange. Nevertheless, the influence of local strain redistribution was expected to disappear at a sufficient distance from
Figure 16. Measured signals at $S_{r e f}$ in Test 1: (a) white noise; (b) earthquake ground motion.

\subsection{Results and discussions}

In all tests, bending strain responses were recorded for 75 seconds with the sampling rate of 100 Hz. Figure 16 shows the strain responses in voltage units (one microstrain corresponds approximately to $12 \mathrm{mV}$ ) and their power spectral densities at the reference sensor $\mathrm{S}_{\text {ref }}$ for two excitations, which were measured from the undamaged condition in the shaking table tests of Test 1 . The power spectral densities indicated that the structural vibration was mainly dominated by the first mode. The first two natural frequencies of the testbed frame were 3.16 and $8.33 \mathrm{~Hz}$ for the undamaged condition, 3.11 and $8.25 \mathrm{~Hz}$ for Case 2, and 3.05 and $8.31 \mathrm{~Hz}$ for Case 17. 
Note that Case 17 was one of serious damage cases among all considered damage cases. The band-pass filter of $2.70-3.30$ and $7.40-9.20 \mathrm{~Hz}$ ( $\pm 10 \%$ of the natural frequencies at the undamaged condition as the band width) were used to obtain the modal strain responses of the first two modes. The averaged ratio of RMS values for different excitations at the undamaged condition were used as the reference values.

\subsubsection{Test 1}

Figure 17 shows the ratios of RMS values of strain responses between sensor S2 and reference sensor $\mathrm{S}_{r e f}$ for the first mode. The largest difference in the ratio values between the two different excitations was $0.78 \%$, which verified independency of the extracted ratio on external excitations as observed in the preceding theoretical formulation and numerical simulations.

The damage indices of sensor S2 for detecting damage L1 and L2 at connection B2 are summarized in Table 4. In Case 1 with damage L1, i.e., entire bottom flange fracture with the reduction of $68.5 \%$ in the bending stiffness, the damage indices were about $-60 \%$ for both excitations with the use of the first mode vibrations but changed to $-70 \%$ with the use of the second mode vibrations. Compared to the damage index extracted from the first mode, the damage index of the second mode had larger discrepancy as the modal strain responses were weak and unclear (see Figure 16). In Case 2 with damage L2, i.e., entire bottom flange and web fracture with the decrease of $99.8 \%$ in the bending stiffness, the damage indices were smaller than $-90 \%$ for two excitations with the first mode vibrations and slightly decreased with the second mode vibrations. As a result, the dominant modes with clear modal responses and high power are highly desirable to increase the accuracy of the calculation of damage index.

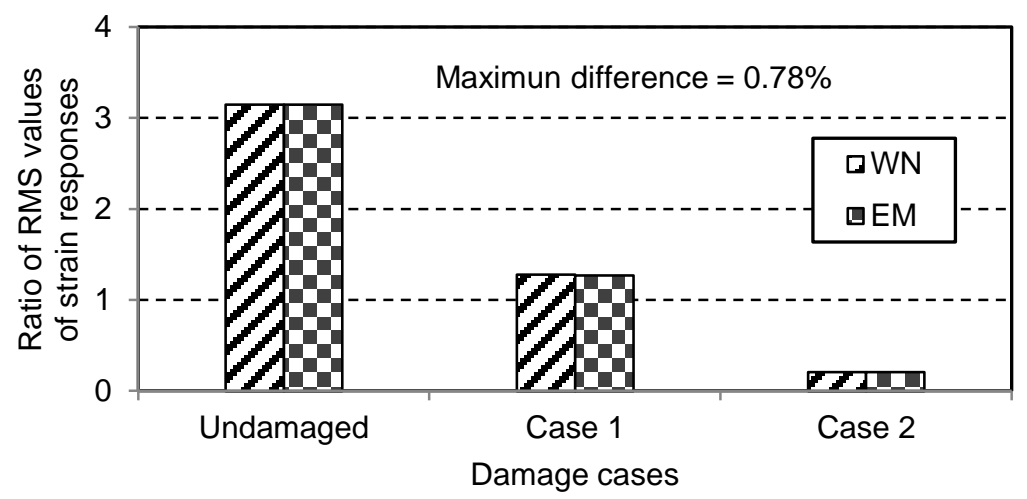

Figure 17. Ratio of RMS of strain responses at $\mathrm{S} 2$ and $\mathrm{S}_{r e f}$ for the first mode in Test 1.

Table 4. Damage index for detecting damage at connection B2 in Test 1.

\begin{tabular}{ccrrr}
\hline \multirow{2}{*}{ Mode } & \multirow{2}{*}{ Excitation } & \multicolumn{3}{c}{ Damage index (\%) } \\
\cline { 3 - 5 } & & Undamaged & Case 1 & Case 2 \\
\hline \multirow{2}{*}{ 1st mode } & WN & 0.0 & -59.5 & -93.5 \\
& EM & 0.0 & -59.7 & -93.4 \\
\hline \multirow{2}{*}{ 2nd mode } & WN & -1.0 & -68.9 & -96.5 \\
& EM & 1.0 & -68.4 & -96.7 \\
\hline
\end{tabular}


499

500

501

502

503

504

505

506

507

508

509

510

511

512

513

514

515

516

517

518

519
Table 5 summarizes the results of Test 2 for different sensor locations. When damage L1 was considered at connection B1 in Case 3, the damage indices at sensors S11 and S12, both placed at $100 \mathrm{~mm}$ (i.e., the beam depth) away from the edge of the fracture, were about $-50 \%$, whereas the damage indices at sensors S13 and S14, both at $150 \mathrm{~mm}$ (i.e., one and half beam depths) away from the edge, were around $-35 \%$ to $-37 \%$. The damage indices at sensors S15 and S16, both attached at $200 \mathrm{~mm}$ (i.e., two beam depths) away from the edge, were $-32 \%$ to $-36 \%$ and consistent with those at S13 and S14. When damage L2 was considered at connection B1 in Case 4, the damage index at the six sensors S11 to S16 was less than $-85 \%$. Compared to the damage index of about $-95 \%$ at sensors S11 and S12, the damage index at sensors S13 to S16 had slight changes of $10 \%$, which was consistent with the findings in the preceding numerical simulations for severe damage DP7; strain sensors needed to be set within two beam depths to guarantee the monotonic relation between the damage index and the reduction of bending stiffness. Note that the values at the different sides of the flange (e.g., S13 and S14, and S15 and S16) varied by 5\% with beam torsional vibrations observed when web links were removed. In conclusion, in order to obtain a stable relation between the damage index and the reduction of bending stiffness, like the damage index curves for sensors S6 to S8 in Figure 11, detecting sensors need to be placed with the distance of at least $1.5 \mathrm{~d}$ but no farther than $2.0 \mathrm{~d}$ from fracture damage as recommended by the previous simulations using the SAC nine-story frame.

Table 5. Damage index for detecting damage at connection B1 in Test 2.

\begin{tabular}{cccccccc}
\hline Damage & \multirow{7}{*}{$\begin{array}{c}\text { Damage index (\%) } \\
\text { case }\end{array}$} & \multirow{2}{*}{ Excitation } & \multicolumn{7}{c}{ S11 } & S12 & S13 & S14 & S15 & S16 \\
\cline { 3 - 8 } Case 3 & AmbE & -47.9 & -51.6 & -35.0 & -36.3 & -32.3 & -35.5 \\
& WN1 & -47.8 & -51.6 & -35.3 & -36.3 & -34.0 & -33.7 \\
& WN2 & -48.9 & -52.1 & -35.9 & -37.4 & -35.0 & -35.4 \\
\hline \multirow{3}{*}{ Case 4 } & AmbE & -96.5 & -94.9 & -93.2 & -89.6 & -90.0 & -85.1 \\
& WN1 & -96.9 & -95.0 & -93.7 & -90.2 & -90.2 & -85.1 \\
& WN2 & -97.0 & -95.0 & -93.8 & -90.2 & -90.3 & -84.9 \\
\hline
\end{tabular}

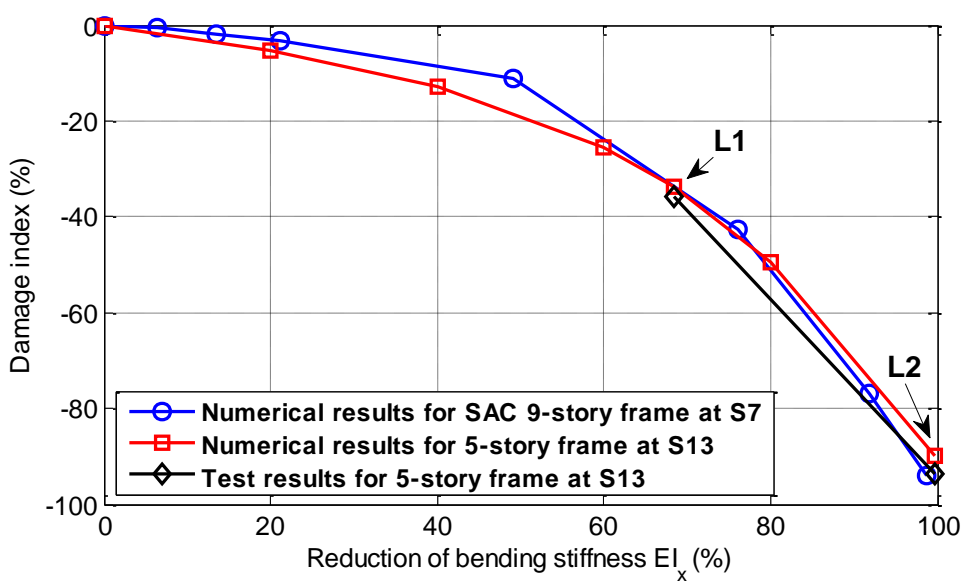

Figure 18. Comparison of the damage index in tests and simulations.

Figure 18 compares the damage index at sensor S13 obtained in tests and simulations. The numerical relationship of the damage index and the reduced bending stiffness at a fractured section was extracted from the bending moment responses of the finite element model of the five- 
526 story frame, in which beams and columns were modeled with beam elements, and the fracture damage at removable connections was modeled with a simplified crack model presented by Sinha et al. [26]. The experimental damage index of $-35 \%$ and $-93 \%$ for damage L1 and L2 matched well with the numerical values of $-33 \%$ and $-90 \%$. In addition, the relation between the damage index $D I$ and the reduction in bending stiffness $E I_{x}$ numerically extracted from the five-story frame and that constructed from the SAC nine-story frame matched at some extent.

\subsubsection{Test 3}

The stability of the damage index was examined by changing the location of damage in the testbed frame. As given in Table 6, the mean values of the damage index at three different connections B2, B6, and B10 were $-59 \%,-55 \%$, and $-52 \%$ for damage L1 and $-91 \%,-92 \%$, and $-95 \%$ for damage L2. The standard deviations in the damage indices for three excitations were less than $0.7 \%$ for damage L1 and $3.9 \%$ for damage L2. The variation was larger for the severer damage condition. The damage index slightly varied for different damage locations but the observed variation was at most $7.8 \%$ for damage L1 and 3.8\% for damage L2. This indicated the general applicability of the damage evaluation based on the proposed damage index for the presented level of damage.

Table 6. Damage index for detecting damage L1 and L2 in Test 3.

\begin{tabular}{cccccrr}
\hline \multirow{2}{*}{$\begin{array}{c}\text { Damage } \\
\text { category }\end{array}$} & Damage & \multicolumn{5}{c}{ Damage index (\%) } \\
\cline { 3 - 7 } & case & AmbE & WN1 & WN2 & Mean & Standard deviation \\
\hline \multirow{3}{*}{ L1 } & Case 5 & -59.6 & -60.4 & -59.6 & -59.9 & 0.5 \\
& Case 6 & -55.2 & -55.8 & -55.2 & -55.4 & 0.3 \\
& Case 7 & -52.0 & -51.4 & -52.8 & -52.1 & 0.7 \\
\hline \multirow{2}{*}{ L2 } & Case 8 & -87.1 & -93.8 & -94.0 & -91.6 & 3.9 \\
& Case 9 & -89.5 & -93.2 & -93.6 & -92.1 & 2.3 \\
& Case 10 & -94.3 & -96.5 & -95.4 & -95.4 & 1.1 \\
\hline
\end{tabular}

\subsubsection{Test 4}

Another important influential factor for the damage index is the increases of bending moment sustained at damage-neighboring connections in the moment redistributions. The existence of severe damage nearby in particular affects the damage index for detecting small damage. Thus, a systematic approach to identify the extent of damage at multiple locations is needed. As this issue will be a focus of further developments of the presented method, in Test 4, preliminary test data for the multiple damage condition was obtained. In Case 12, damage L1 at the left and right sides of a beam-column connection was considered. The damage index at the right side (i.e., connection B3) increased approximately by 5\% with the existence of the left side damage compared to those for the single damage condition in Case 11 (i.e., from $-55.5 \%$ to $-49.3 \%$ in mean). The damage index further increased by $15 \%$ (i.e., from $-49.3 \%$ to $-34.1 \%$ in mean) with the existence of damage L2 in Case 13. In contrast, when damage L2 existed nearby beamcolumn connections in Case 14, the increment was only around 5\%. In Cases 16 and 17, damage L2 was considered at two locations. The results indicate that the influence was negligible at this severity of damage compared to that for the single damage condition in Case 15. 
Table 7. Damage index for detecting damage L1 and L2 at connection B3 in Test 4.

\begin{tabular}{ccrrrrr}
\hline Damage & Damage & \multicolumn{5}{c}{ Damage index (\%) } \\
\cline { 3 - 7 } category & case & AmbE & WN1 & WN2 & Mean & Standard deviation \\
\hline \multirow{4}{*}{ L1 } & Case 11 & -55.9 & -55.1 & -55.5 & -55.5 & 0.4 \\
& Case 12 & -49.7 & -49.1 & -49.1 & -49.3 & 0.3 \\
& Case 13 & -34.8 & -34.1 & -33.5 & -34.1 & 0.7 \\
& Case 14 & -50.3 & -50.9 & -50.4 & -50.5 & 0.3 \\
\hline \multirow{2}{*}{ L2 } & Case 15 & -92.0 & -93.2 & -93.1 & -92.8 & 0.7 \\
& Case 16 & -90.4 & -91.6 & -91.3 & -91.1 & 0.6 \\
& Case 17 & -92.4 & -99.1 & -99.0 & -96.8 & 3.8 \\
\hline
\end{tabular}

\section{CONCLUSIONS}

This paper presented the development of a strain-based damage index for detecting beam fracture damage in steel moment-resisting frames. The effectiveness of the damage index was numerically and experimentally verified using an SAC nine-story steel frame and a five-story steel frame testbed. The notable findings are summarized as follows.

(1) The independency of the presented damage index on the characteristics of external excitations and the selection of vibration modes was verified in numerical simulations and shaking table tests. As the extraction of modal responses required preset band-pass filters, the use of dominant vibration modes with clear responses and high power was highly desirable.

(2) Both in the numerical simulations and experiments, the damage index extracted within a distance of $1.2 d$ ( $d$ is beam depth) from a fracture was largely affected by local strain redistributions induced by the fracture. A distance between $1.2 d$ and $2.0 d$ from the fracture was recommended for evaluating the moment redistributions in steel moment-resisting frames and the reduction in bending stiffness at fractured sections.

(3) The relationship between the damage index $D I$ and the reduction in the bending stiffness $E I_{x}$ of fracture sections was estimated from numerical simulations. The experimental damage indices for damage L1 and L2 in the five-story frame matched very well with the numerical values with the difference of less than 3\%. The relationship allows the evaluation of the damage extent at beam-ends from the damage index extracted from measurement data.

(4) Consistency of the damage index in the evaluation of damage at different locations was verified in experimental studies using the five-story steel testbed frame. The level of variation was at most $7.8 \%$ for damage L1 with fracture of the bottom flange and 3.8\% for damage L2 with fracture of the bottom flange and web.

(5) The proposed method is a strategy for local damage identification. A detecting sensor is used to detect and quantify a seismic fracture at the beam end. Thus, for evaluating the damage state of an entire building, a dense array of sensors is needed to cover all beam ends that may develop fractures or critical regions. However, the number of sensors allocated can be reduced by pre-identifying damage-prone beams at stories sustaining large drift, which are likely to be the lower stories, or by integrating other information (e.g., maximum story responses measured using accelerometers). Monitoring beams of large-deformation floors would be effective in assessing the safety of the building.

(6) Future studies are needed to quantify and systematically filter out the influence of neighboring beam damage on the damage index when there is multiple beam damage, and to 
601

602

603

604

605

606

607

608

609

610

611

612

613

614

615

616

617

618

619

620

621

622

623

624

625

626

627

628

629

630

631

632

633

634

635

636

637

638

639

640

641

642

643

644

645

646

evaluate the influence of other damaged structural components (e.g., breakdown of the composite action in concrete slabs) on the damage index. It is also desirable to generalize the relationship between the damage index and the damage extent for different configurations of frame dimensions and beam sizes.

\section{ACKNOWLEDGEMENTS}

The authors gratefully acknowledge funding support offered by the General Collaborative Research program of the Disaster Prevention Research Institute, Kyoto University under Project Number 24A-05 (PI: Masahiro Kurata). The greatest of thanks go to Dr. Lin Xuchuan for numerical simulation work using Marc software and Dr. Tang Zhenyun and Ms. Mayako Yamaguchi for assistance offered in the experimental work.

\section{REFERENCES}

1. Nakashima M. Reconnaissance report on damage to steel buildings structures observed from the 1995 Hyogoken-Nanbu (Hanshin/Awaji) earthquake, Abridged English edition. Steel Committee of Kinki Branch, the Architectural Institute of Japan (AIJ), 1995.

2. Mahin S. Lessons from damage to steel buildings during the Northridge earthquake. Engineering Structures 1998; 20(4-6): 261-270. DOI: 10.1016/S0141-0296(97)00032-1.

3. Fan W, Qiao P. Vibration-based damage identification methods: a review and comparative study. Structural health monitoring 2011; 10(1): 83-111. DOI: 10.1177/1475921710365419.

4. Celebi M, Sanli A, Sinclair M, Gallant S, Radulescu D. Real-time seismic monitoring needs of a building owner - and the solution: a cooperative effort. Earthquake Spectra 2004; 20(2), 333-346. DOI: 10.1193/1.1735987.

5. Todorovska MI, Trifunac MD. Impulse response analysis of the Van Nuys 7-storey hotel during 11 earthquakes and earthquake damage detection. Structural Control and Health Monitoring 2008; 15(1): 90-116. DOI: 10.1002/stc.208.

6. Sohn H, Farrar CR. Damage diagnosis using time series analysis of vibration signals. Smart Materials and Structures 2001; 10(3), 446-451. DOI:10.1088/0964-1726/10/3/304.

7. Naeim F, Hagie H, Alimoradi A, Miranda E. Automated post-earthquake damage assessment and safety evaluation of instrumented buildings. A Report to CSMIP (JAMA Report No. 2005-10639), John A. Martin \& Associates, 2005.

8. Kalkan E, Banga K, Ulusoy HS, Fletcher JPB, Leith WS, Reza S, Cheng T. Advanced earthquake monitoring system for U.S. Department of Veterans Affairs medical buildingsinstrumentation. U.S. Geological Survey Open-File Report 2012-1241, 143 p, 2012.

9. Ji X, Fenves G, Kajiwara K, Nakashima M. Seismic damage detection of a full-scale shaking table test structure. Journal of Structural Engineering 2011; 137(6): 14-21. DOI: 10.1061/(ASCE)ST.1943-541X.0000278.

10. Chung Y. Existing performance and effect of retrofit of high-rise steel buildings subjected to long-period ground motions. Doctoral Dissertation, Kyoto University, Japan, 2010.

11. Li S, Wu Z. Development of distributed long-gage fiber optic sensing system for structural health monitoring. Structural health monitoring 2007; 6(2): 133-143. DOI: $10.1177 / 1475921706072078$. 
647

648

649

650

651

652

653

654

655

656

657

658

659

660

661

662

663

664

665

666

667

668

669

670

671

672

673

674

675

676

677

678

679

680

681

682

683

684

685
12. Hong $\mathrm{W}, \mathrm{Wu} \mathrm{Z}$, Yang $\mathrm{C}$, Wan $\mathrm{C}, \mathrm{Wu}$ G. Investigation on the damage identification of bridges using distributed long-gauge dynamic macrostrain response under ambient excitation. Journal of Intelligent Material Systems and Structures 2012; 23(1): 85-103. DOI: 10.1177/1045389X11430743.

13. Razi P, Esmaeel RA, Taheri F. Improvement of a vibration-based damage detection approach for health monitoring of bolted flange joints in pipelines. Structural health monitoring 2013; 12(3): 207-224. DOI: 10.1177/1475921713479641.

14. Mujica LE, Vehi J, Staszewski W, Worden K. Impact damage detection in aircraft composites using knowledge-based reasoning. Structural health monitoring 2008; 7(3): 215230. DOI: $10.1177 / 1475921708090560$.

15. Lynch JP, Loh KJ. A summary review of wireless sensors and sensor networks for structural health monitoring. The Shock and Vibration Digest 2006; 38(2): 91-128. DOI: 10.1177/0583102406061499.

16. Pakzad SN, Fenves GL. Statistical analysis of vibration modes of a suspension bridge using spatially dense wireless sensor network. Journal of Structural Engineering 2009; 135(7): 863-872. DOI: 10.1061/(ASCE)ST.1943-541X.0000033.

17. Kurata M, Kim J, Lynch JP, van der Linden GW, Sedarat H, Thometz E, Hipley P, Sheng LH. Internet-enabled wireless structural monitoring systems: Development and permanent deployment at the New Carquinez suspension bridge. Journal of Structural Engineering 2013; 139(10): 1688-1702. DOI: 10.1061/(ASCE)ST.1943-541X.0000609.

18. Park G, Inman DJ. Structural health monitoring using piezoelectric impedance measurements. Philosophical Transactions of the Royal Society A 2007; 365: 373-392. DOI: 10.1098/rsta.2006.1934.

19. Kurata M, Li X, Fujita K, Yamaguchi M. Piezoelectric dynamic strain monitoring for detecting local seismic damage in steel buildings. Smart Materials and Structures 2013; 22, 115002. DOI:10.1088/0964-1726/22/11/115002.

20. Chopra AK. Dynamics of structures: theory and applications to earthquake engineering, 2th edition. Prentice Hall, 2001.

21. FEMA-355C. State of the art report on systems performance of steel moment frames subject to earthquake ground shaking, 2000.

22. MSC Software Corporation. http://www.mscsoftware.com/product/marc [30 Dec. 2013].

23. Ohtori Y, Christenson RE, Spencer BF, Dyke SJ. Benchmark control problems for seismically excited nonlinear buildings. Journal of Engineering Mechanics 2004; 130(4): 366-385. DOI: 10.1061/(ASCE)0733-9399(2004)130:4(366).

24. Measurement Specialties. http://www.meas-spec.com [30 Dec. 2013].

25. Civionics, LLC. http://www.civionics.com [30 Dec. 2013].

26. Sinha JK, Friswell MI, Edwards S. Simplified models for the location of cracks in beam structures using measured vibration data. Journal of Sound and Vibration 2002; 251(1):13-38. DOI: $10.1006 /$ jsvi.2001.3978. 